\title{
Forensic age estimation in living individuals: methodological considerations in the context of medico-legal practice
}

This article was published in the following Dove Press journal:

Research and Reports in Forensic Medical Science

14 October 2015

Number of times this article has been viewed

\section{Daniel Franklin \\ Ambika Flavel \\ Jacqueline Noble \\ Lauren Swift \\ Shalmira Karkhanis}

School of Anatomy, Physiology and Human Biology, Centre for Forensic Anatomy and Biological Sciences, The University of Western Australia, Crawley, WA, Australia
Correspondence: Daniel Franklin School of Anatomy, Physiology and Human Biology, Centre for Forensic Anatomy and Biological Sciences, The University of Western Australia, M420, 35 Stirling Highway,

Crawley 6009, WA, Australia

Tel +61864881232

Fax +6I 864887285

Email daniel.franklin@uwa.edu.au

\begin{abstract}
The reconciliation of skeletal and chronological age is of paramount concern in the context of criminal proceedings involving living individuals, who frequently lack any associated identification documentation, and are referred to the criminal justice system. It is important to appreciate that skeletal and chronological ages are not the same measurement of time-since-birth, and depending on the analytical approaches applied, there will be an inherent source of variation between estimated (biological: skeletal, physical, and psychological) and actual (legal) age. Given the evidentiary value attached to the estimation of age based on the subjective assessment of biological and psychological developmental attributes, it is timely to consider current approaches toward achieving the latter. The aim of this review is to first explore a selection of circumstances that result in requests for forensic age assessment in living individuals. Issues pertaining to competency to perform an assessment, sources of error that may be introduced, and how to accordingly quantify the level of uncertainty in the final estimation are then considered. This logically leads into discussions of the necessity for population-specific statistical biological data. Current methods based on psychological development, dental status, and skeletal maturation are then reviewed. The review concludes by exploring future research and practical directions in the context of medico-legal practice and social consequences.
\end{abstract}

Keywords: age estimation, skeletal growth, biological variation, dental development, forensic medicine, forensic radiology, virtual anthropology

\section{Introduction}

The work of forensic scientists and allied professionals is wide reaching and important; these practitioners are holders of a public trust because a portion of the vital affairs of other people is placed into their hands by virtue of their role in the medico-legal system. This is perhaps most poignant when a forensic practitioner is requested to perform an assessment of age in a living individual for the purpose of providing information that carries significant evidentiary value in legal decisions that determine future outcomes for individuals displaced from their original homeland.

This review considers some of the more common circumstances that result in living individuals without documentary evidence of identity (and thus age) entering the justice system. It also discusses who should be deemed qualified to perform the requisite assessment(s), and the processes of selecting an appropriate method(s). The review concludes with some consideration of future directions in the discipline. 


\section{Legal requirements for age estimation in the living \\ Refugee and asylum seekers}

A proportion of the world's population is presently in a state of involuntary flux resultant from displacement by war, internal conflict, or natural disasters. According to the United Nations High Commissioner for Refugees (UNHCR), almost half of people forcibly displaced from their homes are children, representing a demographic at particular risk of "abuse, neglect, violence, exploitation, trafficking or forced military recruitment"1 and in need of international protection.

The Convention on the Rights of the Child (1990) has been signed by 193 of the 195 United Nations (UN) member nations. It stipulates that States Parties shall respect and ensure the rights of each child within their jurisdiction without discrimination; a child is defined as being $<18$ years of age, which places the onus on member States to protect children in their jurisdiction. A particular difficulty arises, however, when individuals claiming to be children have no legitimate identity documentation to evidence their assertion.

The UNHCR Guidelines on Policies and Procedures in Dealing with Unaccompanied Children Seeking Asylum (1997) advise that if chronological age is uncertain, an unidentified child should be given the benefit of doubt, and that requisite age assessments should accordingly consider whether "an individual demonstrates an 'immaturity' and vulnerability that may require more sensitive treatment". The guidelines propose that age assessments should be based on a combination of criteria, including physical appearance and psychological maturity. Any scientific procedures should facilitate the quantification of uncertainty (margins of error) and be in accordance with the ethical treatment of children ${ }^{2}-$ both safe (eg, minimally invasive - both physically and in relation to minimizing deleterious radiation from any medical imaging) and respectful of human dignity. ${ }^{3,4}$

UNHCR Detention Guidelines (2012) refer to asylum seekers as persons applying for refugee status (Article 1 of the Convention relating to the Status of Refugees (1951), amended by the 1967 Protocol: A person who owing to a well-founded fear of being persecuted for reasons of race, religion, nationality, membership of a particular social group or political opinion, is outside the country of his nationality and is unable or, owing to such fear, is unwilling to avail himself of the protection of that country; or who, not having a nationality and being outside the country of his former habitual residence as a result of such events, is unable or, owing to such fear, is unwilling to return to it) as well as other persons seeking complementary, subsidiary, or temporary forms of protection. The guidelines recommend that children (in particular) should not be detained while seeking asylum, and serve as a reminder that minors have the right to not be separated from their parents against their will. ${ }^{5}$ For receiving authorities (governments and decision makers), this presents substantial logistical implications, as there is no guarantee of compliance with non-separation. Australia, for example, has a mandatory detention policy, ${ }^{6}$ and in 2014, a total of 983 children were held in immigration detention facilities, either in Australian territories or in Nauru (South Pacific island nation hosting detention centers to process asylum seekers and refugees arriving in Australia by boat) for an average period of 231 days. $^{\text {? }}$

From a humanitarian perspective, the detention of minors is a serious and real concern, as teenagers are particularly susceptible to mental and emotional distress, which can lead to self-harm. ${ }^{7}$ However, separation of those minors from their immediate families, which could occur if erroneously deemed to be legally an adult, would arguably be worse. Child asylum seekers, and children left behind by families seeking asylum, are particularly vulnerable to human trafficking, whether on-route to their new destination, while in detention awaiting processing, or after relocation in an unfamiliar environment. ${ }^{8}$

\section{Human trafficking}

The UN Protocol to Prevent, Suppress and Punish Trafficking in Persons, especially Women and Children (2000) definition of human trafficking implies the exploitation of a person by means of the threat or use of force. ${ }^{9}$ The most recent reports state that trafficking victims were identified in 124 countries (2010-2012) and are thus considered a global issue. A total of 160 member States ratified the Trafficking in Persons Protocol, with $90 \%$ of members criminalizing trafficking in persons. Such legislation is presently nonexistent in nine countries, with an additional 18 others having some form of legislation, albeit inadequate to offer the protection required; as a result, it is estimated that, as of 2014, more than two billion people are not fully protected by the Trafficking in Persons Protocol. ${ }^{10}$

Detection of trafficking victims is increasing, as is the ratio of child victims relative to adults, particularly in Africa and the Middle East. ${ }^{11}$ On average, one in three trafficking victims is a child, which represents an increase of 5\% from the previous study period of 2007-2010. ${ }^{10}$ From information reported by 80 countries encompassing the period 2010-2012, 31,766 trafficking victims of known age and sex were identified; $12 \%$ of those were boys, and $21 \%$ were girls, all $<18$ years of age. ${ }^{10}$ 
There are a variety of motivations for people trafficking, including: sexual exploitation; forced labor in, for example, catering, domestic servitude, textile production, construction, forestry, mining, and agriculture; adoption; forced military recruitment; begging; and organ harvesting. ${ }^{10,12}$ Reported transnational trafficking usually involves victims from less developed countries, from regions including South and East Asia, Central Europe, sub-Saharan Africa, and South America. It is also known that trafficking occurs in more developed countries, including North America and in Western and Central Europe, and the Middle East. Domestic trafficking is common, and often more widespread than the international movement of people; again, the flow of people is usually from poorer rural areas to richer urban environments. ${ }^{8}$

Children from low socioeconomic backgrounds are vulnerable to trafficking, fueled by the demand for cheap labor, young brides, prostitution and pornography, and clandestine adoption. ${ }^{8,13}$ Once trafficked, children are often required to engage in criminal activities, thereby instigating their admission into the local punitive system, often in the absence of, or with, falsified identity documents.

\section{Criminal responsibility}

The age of criminal responsibility in much of the developed world is 10 years (eg, Australia, New Zealand) but is as young as 7-8 years (eg, India, Jordan, Indonesia); children under this age cannot be arrested or charged with a crime. A more controversial concept is that of doli incapax, which is the presumption that a child is incapable of committing a crime under legislation or common law and applies to children, generally in the age of 13 years (eg, New Zealand) or 14 years (eg, Australia), depending on jurisdiction. ${ }^{14-16}$ The UN published guidelines to the effect that no children "under the legal age of criminal responsibility should be subject to criminal charges" and is openly critical of nations with an age of criminal responsibility of 12 years or younger. ${ }^{17}$ Further to this, the UN suggests that nations "independently and objectively" ascertain the age of a child within their jurisdiction whose age is not definitively known, ${ }^{17}$ as would be the case for trafficked children.

Young people between the age of culpability (or doli incapax if applicable) and adulthood (17-21 years depending on jurisdiction) are responsible for their actions but do not have the full criminal liability of an adult. Individuals in this age group are preferably subjected to rehabilitation rather than punishment. ${ }^{14}$ Offenders who are not classed as children, but instead deemed to be legally adult, accordingly enter the adult justice system, albeit some jurisdictions (eg, the UK) recognize the benefits of imprisoning young adults separately from adults $>25$ years of age. ${ }^{18}$

This segregation is justified in order to limit juvenile exposure to adult correctional attitudes, philosophy, and culture, as well as to protect youths from sexual and physical violence. ${ }^{19,20}$ Incarceration can expose vulnerable individuals to additional emotional and physical risk because some of the coping mechanisms that are required to adjust to the prison environment include antisocial behavior, self-injury, and depression. ${ }^{19}$ In addition, the incidence of reoffending reportedly increases when juveniles are detailed in adult correctional facilities. ${ }^{20}$ These legal age groupings, and the implications for the criminal justice system, put the onus on individual jurisdictions to clearly define not only the age of majority but also the age of minority of individuals within their respective judicial systems.

\section{Child pornography}

Child pornography is generally accepted to refer to the visual assessment of still and video images of individuals under the age of consent ("Age of consent refers to the minimum age of a person with whom another person is legally permitted to engage in sexual activity". ${ }^{21}$ Age of consent varies by jurisdiction, from 12 years (eg, Chile, Mexico, Paraguay) to 18 years (eg, Egypt, Guatemala, Haiti), albeit it is most frequently $\sim 16$ years of age. ${ }^{21}$ The age of consent, however, is irrelevant in the context of pornography in many jurisdictions, which typically can only legally involve individuals who are at least 18 years of age. Some jurisdictions (eg, Germany) make a distinction between child pornography that involves children $<14$ years of age and juvenile pornography engaging adolescents $<18$. 22 "Child pornography means any representation, by whatever means, of a child engaged in real or simulated explicit sexual activities or any representation of the sexual parts of a child for primarily sexual purposes". ${ }^{23}$ Most jurisdictions consider the production, distribution, reception, and possession of images of child pornography illegal.

It is clearly imperative that the identification of pornographic material involving subjects $<18$ years of age is performed accurately; because the individual(s) in question may not be available for an actual physical assessment, age assessment is usually based solely on visual inspection of secondary sexual characteristics. ${ }^{24}$ The latter is not necessarily straightforward, with recent research demonstrating that the visual assessment of suspected pedo-pornographic images can result in the incorrect identification of adults as children $67 \%$ of the time. ${ }^{25}$ This was deemed to be due to 
the differential timing of developmental maturity between populations. This research lends further support to the importance of due consideration of population specificity in relation to forensic age assessment (see "The necessity for population-specific statistical data"), albeit in the context of child pornography, it is especially important that children are not mistakenly identified as adults.

\section{Falsification of age}

Age estimation of the living can be required in cases involving individuals who deliberate falsify their birth year to increase (or lower) their age to, for example, legally marry, achieve the required age threshold for employment in a particular industry, or enlist in the military. In 2010, the UN launched a 2-year campaign, "Zero under 18", whereby all member States were encouraged to raise the age of voluntary military recruitment to a minimum of 18 years. ${ }^{26}$ All United Nations Security Council permanent member States (excluding the UK) only recruit adults into the armed forces ${ }^{27}$ as recommended by UNHCR. Altering a person's age for the purposes of enlistment was prevalent during the first and second world wars and persists in the modern era.

Falsification of age in professional sports is another relatively common practice, particularly by individuals representative of global regions facing economic hardship. ${ }^{28}$ In the sporting industry that caters for youths, misrepresentations of chronological age are regularly reported and thus require an appropriate investigation and age verification. In such circumstance, substantiation of age is usually ascertained based on the assessment of skeletal development, which reportedly has a risk of false negatives and false positives. ${ }^{29}$

\section{Competency, source(s) of error, and quantification of uncertainty}

A recent inquiry by the Australian Human Rights Commission ${ }^{7,30}$ into suspected people smugglers claiming to be children highlighted the growing need for a more informed understanding of age estimation assessments performed in living individuals. The focus of the enquiry was a group of 180 Indonesian crewmembers under investigation for illegally bringing asylum seekers into Australia (since 2008) and whose age was in legal dispute. In those cases, the Australian Federal Police (AFP) based their legal determination of adult status ( $>18$ years of age) on an independently sourced assessment of hand-wrist radiographs. The method applied ${ }^{31}$ was considered to be a scientific means of establishing chronological age based on the degree of skeletal maturity relative to "full development" of the bone(s) assessed. The latter presumption, however, is not only contrary to the stated purpose of the technique, but also against the advice of professional bodies, including the Royal Australian and New Zealand College of Radiologists, the Australian and New Zealand Society for Paediatric Radiology, the Australasian Paediatric Endocrine Group, and the Division of Paediatrics, Royal Australasian College of Physicians. As a consequence, many Indonesian nationals who were subsequently accepted to have been children at the time of the offense were frequently detained for prolonged periods (some up to 948 days) in adult correctional facilities.

In 2011, in response to increasing criticism from international and humanitarian communities, Australian Commonwealth agencies ceased relying on the assessment of age based on the analysis of hand-wrist radiographs. Assessment of dental status has similarly not been utilized as proof of age of majority in Australia. ${ }^{32}$ Instead, the Department of Immigration and Citizenship began processing age disputes using interviews designed to assess psychological and physical indicators of maturity, and where a wide margin of error is allowed; only those individuals subsequently deemed adult are then referred to the AFP. Independent reports have since criticized the latter method of age assessment based on it being both arbitrary and emotionally invasive $e^{7,33}$ which has all but ignored any skeletal indicators of age due to a lack of a clear understanding of the parameters by which they are most useful.

A large body of scholarly reference texts and written guidelines for the assessment of age have been published ${ }^{2,34-36}$ to assist law enforcement agencies and social workers to determine the age of a person whose birthdate is in question. All of those sources cited emphasize the importance of using qualified personnel to perform the assessment, who must have a clear understanding of the appropriate application of the method, which must be a proven scientific technique(s) with a known rate of error. An extra level of error will be introduced into any age estimate through the misapplication of the technique, thus highlighting the importance of an appropriate level of training and experience; it is not simply knowing which method is appropriate to apply in any given scenario, but also how to correctly apply that method and report the appropriate statistical quantification of error and uncertainty in the final estimation.

\section{The necessity for population-specific statistical data}

It is an established fact that age assessment methods, such as those based on the analysis of skeletal maturity, ${ }^{31,37,38}$ dental 
development, ${ }^{39-41}$ or sexual maturity, ${ }^{25,42}$ are most accurate when applied to the individuals from the population from which those standards are derived. The same relationship is true for other skeletal attributes (eg, sex and stature) and there are numerous published examples in the literature detailing how, upon application to an individual foreign to the original reference population, higher error rates result. ${ }^{43-45}$ This potentially compromises (or limits the applicability of) a method that may have had an acceptable stated error in the original reference population.

A particular challenge faced by many forensic practitioners is that the populations most in need of reliable age assessment standards (eg, comprising individuals from localized geographic regions that are more likely to enter the criminal justice system - such as people smugglers) are disproportionately underrepresented in the published literature; specifically, there is a scarcity of scientific standards relevant to those groups. Many present standards are based on the analysis of Europeans (England and Germany in particular) and North Americans. In addition, a large proportion of extant standards were formulated several generations ago, based on the analysis of archeological, military, or cadaveric samples, and thus, due to the complex interrelationship of increasing intermarriage, global migrations, and other environmental factors, may not accurately reflect the modern population in a given geographic region. Contemporary global standards that account for secular change are thus both long overdue and duly required.

\section{Age estimation in the living - method and practice} The present review considers recent published literature, with a specific focus on studies (presented in sections corresponding to physical, psychological, and skeletal developmental indicators) appropriate for age estimation in the context of asylum seekers and human trafficking. It is important to note, however, that the scope of this review is not all encompassing and thus those practitioners seeking a more detailed treatise on this topic should accordingly undertake a duly diligent investigation of the published literature relating to their specific requirement(s).

\section{Secondary sexual development}

A preliminary assessment of age can be subjectively performed based on the presence and prevalence of secondary sexual characteristics that become prominent throughout puberty (eg, breast development, the presence of pubic hair, and the laryngeal prominence in males). These characteristics develop as a result of sexual maturity. While these features highlight sexual dimorphism, their use as a tool for evaluating age within a living population is dubious. ${ }^{46}$ Many factors can either inhibit or accelerate the development of secondary sexual characteristics, most notable of which is varied ethnicity, geographic location, and individual body shape/size..$^{47,48}$

Research by Wu et a ${ }^{48}$ aimed to determine trends relating to the development of secondary sexual characteristic for African, Caucasian, and Hispanic American girls aged between 8 and 16 years. In particular, the development of the breasts and pubic hair was of concern. The results of this investigation showed that the mean age for development of pubic hair varied between 9.5 years for African American, 10.5 years for Caucasian, and 10.3 years for Hispanic girls. A similar trend was likewise observed when considering breast development, with $49.4 \%$ of African American girls experiencing bud development, by age 9 compared to $15.8 \%$ of Caucasian and $24.5 \%$ of Hispanics at the same age. The results of this study thus imply that the development of secondary sexual characteristics is not an appropriate method by which age of living individuals can be ascertained, especially within an ethnically and geographically diverse group of individuals. The same basic relationship between sexual maturity markers and chronological age was also demonstrated to occur in an ethnically diverse cohort of American boys. ${ }^{47}$ African American boys were advanced in their degree of genital and pubic hair development by an average of 1-2 years compared to Hispanic and non-Hispanic white boys. Again, this further confirms significant interethnic variation in the timing of sexual maturity.

The assessment of the development of secondary sexual characteristics toward facilitating an estimate of living age was further explored, and subsequently discredited, by Greil and Kahl. ${ }^{49}$ This study investigated development in $>16,000$ German children (equally distributed by sex) between 8 and 17 years of age. The timing of the initial development and growth of female breast buds and pubic hair in both sexes was quantified. Although their results demonstrated that the female developmental trajectory of the breasts and pubic hair is similar, there was a wide degree of variation within the sample. For example, the first onset of breast development was found to occur as early as 8.1 years in some girls (1\%), with fully complete development observed as early as 14.2 years of age. The apparent age variation in breast development was attributed to the different body shapes of the girls studied. For example, girls who had a leptomorphic (tall and lean) physique developed on average 3 years slower than girls 
who were assessed as having a more pyknic (rounder, fuller shape) somatotype.

\section{Psychological development}

Establishing the legal age of suspected juveniles often involves (by necessity) a multidisciplinary evaluation that not only includes a physical and developmental evaluation but also a psychological assessment. ${ }^{50}$ As it is well established that growth and maturation are subject to variation in relation to (often unknown) environmental conditions, ${ }^{36,51-53}$ it is important to consider applying a multifactorial approach that considers and/or includes other age indicators independent of the timing of attainment of skeletal developmental milestones. The Child Asylum Claim guideline by the UNHCR recommends multidisciplinary age assessments that consider both the physical appearance and age of the children, as well as their psychological maturity. ${ }^{54}$

The Royal College of Physicians (RCP) emphasizes the importance of understanding the specific social history of an individual child in association with other physical methods of age estimation. ${ }^{50,51}$ Social history is based on (but not limited to) the following factors: lifestyle, familial role in country of origin, and the type of education received. These factors all contribute to psychological development, and by association the psychological age, of a child, and thus, as the RCP suggest, should be duly considered as a requirement in the derivation of a holistic estimation of living age.

The onset of puberty (both physical and psychological) is another factor that can be considered toward deriving an age estimate; however, in the interest of accuracy, the latter should be performed in relation to extant knowledge of the social history and specific cultural environment of the unidentified child. Malnutrition and illness can delay the physical onset of puberty, ${ }^{51,55,56}$ which may result in persons appearing younger than they are based on pubertal development, thus resulting in an underestimation of actual chronological age. Conversely, the average age of the onset of puberty in females from the Indian subcontinent has been shown to occur slightly earlier (by $0.2-0.8$ years compared to Caucasian females); ${ }^{57,58}$ this would result in the overestimation of chronological age of the Indian children if they were assessed according to Caucasian developmental norms. ${ }^{51}$

The psychological evaluation of children for age estimation requirements is performed using a variety of approaches specific to different geographical jurisdictions. "So "Social assessments" (eg, an interview with the child accompanied by a brief visual physical assessment) are performed in Austria, Germany, Ireland, Sweden, the UK, and the US; however, the level of detail achieved in these assessments related to the social history of the child, and actual method that underpin these assessments, varies considerably. ${ }^{59}$ These methods are used to collect data relating to the following criteria: familial relationships, age of siblings, education history, and social exposure. These social assessments can also fail to consider psychological maturity, and are therefore inadequate as a holistic approach to age estimation in youth. ${ }^{59}$

It is important to note that there is some degree of controversy surrounding the psychological assessment of age in relation to adequate training and education of personnel appointed to conduct such interviews. ${ }^{50}$ In some cases, a child will be interviewed by a customs or immigration officer, whereas in other situations, the interview will be performed by a police officer accompanied by a social worker. ${ }^{59}$ In the interest of obtaining the most accurate profile possible, however, the most appropriate personnel to perform the requisite assessment in such cases are child psychologists, as they have the necessary education, training, and experience to work with, and relate to, children, and to thereafter evaluate their psychological age based on an appropriately designed interview. ${ }^{59}$

In the assessment of psychological development for age estimation purposes, it is thus both necessary and essential that a holistic approach is applied when evaluating the age of a minor within the framework of the justice system. This includes an in-depth psychological evaluation that takes into consideration cultural factors and social history. ${ }^{59}$ It is also poignant to consider issues pertaining to psychological assessment for age in developmentally disabled/delayed children, with the UNHCR (Guidelines on International Protection: Child Asylum Claims under Articles 1(A) 2 and 1(F) of the 1951 Convention and/or 1967 Protocol relating to the Status of Refugees) stating:

\begin{abstract}
Being young and vulnerable may make a person especially susceptible to persecution. Thus, there may be exceptional cases for which these guidelines are relevant even if the applicant is 18 years of age or slightly older. This may be particularly the case where persecution has hindered the applicant's development and his/her psychological maturity remains comparable to that of a child. ${ }^{54}$
\end{abstract}

\section{Dental development}

The complex and sequential process of dental development is one of the longest for any organ or tissue in the human body, beginning at $\sim 6$ weeks in utero and ending 
at 18-25 years of age. ${ }^{2}$ Dental mineralization, compared to skeletal development, is widely considered the most accurate indicator of chronological age in subadults; this is because the timing of dental development is less likely to be influenced by extrinsic environmental factors, such as nutritional status and chronic illness. ${ }^{60}$ Accordingly, the radiographic visualization and analysis of tooth formation stages are the foundation of many established age estimation techniques. Furthermore, The Study Group on Forensic Age Diagnostics recommends the radiographic evaluation of dental status as one of the diagnostic procedures for age estimation in living individuals, ${ }^{61}$ albeit it is worth considering AlQahtani's ${ }^{62}$ suggestion that "The sequence of eruption and tooth count may be the only way to estimate the age of a living infant, as radiographs are contraindicated in this age group and the difficulty in obtaining a radiograph from an infant is predictable" (pp 149-150).

There are, however, other logistical considerations; increasing global migration and intermixing of the gene pool have introduced a potential source of variation in the age of attaining dental developmental milestones. ${ }^{63}$ Similarly, factors such as socioeconomic status and genetic variability $^{64-67}$ further contribute to population differences in dental development and eruption. The most practical solution toward achieving accurate dental age estimations in any specific jurisdiction is to formulate contemporary standards for the specific population of legal interest. It is thus widely acknowledged that age estimation standards suitable for forensic practice should meet specific methodological requirements, such as the analysis of an adequately large sample that is evenly distributed by age and sex (this attempts to ensure representativeness of the population studied), a clearly defined and reproducible methodological approach supported by statistical quantification of intra- and interobserver accordance, associated demographic data of the reference population (eg, socioeconomic status, genetic information) and the quantification of the predictive accuracy and/or uncertainty of the final age estimate..$^{43,61}$

\section{Dental age estimation in children}

Subadult dental age estimation primarily involves the application of atlas style and/or measurement/scoring-based techniques. The former characteristically requires comparison of dental radiographs that show distinct stages of tooth development, eruption, and exfoliation to composite dental development atlases, such as those produced by Schour and Massler ${ }^{68,69}$ and Ubelaker. $^{70}$ Those techniques are based on scoring/measuring stages of tooth development and calculating maturity scores that are compared to reference tables and graphs. The dental standards of Moorrees et $\mathrm{al}^{41}$ and Demirjian et $\mathrm{al}^{40}$ are among the most popular methods that score the developmental stages of individual teeth and allow the formulation of sex-specific age estimations.

The Moorrees $^{41}$ technique includes diagrammatic and written descriptors for the morphology of the developing dentition and provides normative data for dental development for the specific purpose of assessing growth acceleration or retardation. Subsequently, this methodological approach has been employed to develop age estimation standards suitable for forensic application and has been validated in other populations. ${ }^{71-74}$ Previous research has indicated that the application of the Moorrees standards potentially results in the consistent underestimation of age, for example: -0.91 years in a mixed ethnicity population from South Africa; ${ }^{75}$ and -0.10 years (standard deviation [SD] 0.97 years) in a British population of mixed ethnicity and temporal origin. ${ }^{74}$ Further, a technical difficulty in using the Moorrees standards is that the results are presented in a cumbersome format and the graphs require manual interpretation, unlike the Demirjian standards, which can be interpreted using a contemporary computational approach. Hence, Harris and Buck " "reverse engineered" the graphs of Moorrees et al to provide normative data for tooth development of the ten permanent teeth analyzed in the original study. This presented the mean ages of dental development and the associated SDs in a tabular format, thus more usable in terms of statistical application and computerization of the method.

The Demirjian standards, similar to the Moorrees method, are based on scoring seven mandibular teeth using written and pictorial criteria to calculate a dental maturity score for estimating age in a clinical and/or forensic context. With specific reference to the dental age standards developed by Demirjian et al, ${ }^{40}$ there has been a multitude of validation studies exploring the reliability and accuracy of that method in populations foreign to the original reference sample, for example: Australian, ${ }^{77}$ Turkish, ${ }^{78}$ Indian, ${ }^{79}$ South African, ${ }^{75}$ and Belgian. ${ }^{80}$ The use of Demirjian standards in an Australian population resulted in the mean overestimation of chronological age by 0.99 years in children $<14$ years of age. ${ }^{77}$ Similarly, overestimation was also reported in the Indian (3.04 years and 2.82 years in males and females, respectively), ${ }^{79}$ Turkish (0.36-1.43 years in males and $0.50-1.44$ years in females), ${ }^{78}$ and South African (0.89 years $)^{75}$ populations. The Demirjian technique, however, cannot be applied in cases where the dental remains are fragmented or where there are bilaterally absent teeth and dental malformations. 
Further, in situations where scoring of any of the seven teeth is unfeasible, an estimated score for the missing tooth is used, which increases the bias associated with the age estimation. This technique also assigns equal weight to each tooth in the age estimation method instead of tooth-specific standards. ${ }^{81}$

The technique developed by Demirjian et al has also been used to develop predictive models for age estimation with promising results in (for example) an Australian (95\% confidence interval $[\mathrm{CI}] \pm 1.80$ years $)^{77}$ and a Belgian population $(95 \% \mathrm{CI} \pm 1.89$ years and \pm 2.06 years in males and females, respectively). ${ }^{80}$ Similarly, polynomial regression models have also been developed for a Western Australian population using the Moorrees standards, demonstrating potentially significant forensic applicability (SD \pm 0.998 years $).{ }^{82}$

\section{Dental age estimation in adolescents}

Age of majority is an important legal issue because it carries evidentiary value toward the possible prosecution of an individual and thus potentially determines the correctional facility in which a person may eventually be detained. Incorrect assessment in cases where age of majority is at issue may lead to significant human right breaches (eg, mistreatment of the individual, family separation, and deprivation of liberty). ${ }^{30}$ Because the timing of dental development shows biological variation between individuals, precise estimations of age are not possible; accordingly, an age range with CIs is the most appropriate expression of an age estimation. ${ }^{30,81}$

In assessing age of majority, there are typically less dental developmental markers available for analysis - a consequence of the developmental timespan of the human dentition. In the late adolescent to early adult age range, most dental age approaches involve analyzing third molar development based on the methodological approach of Demirjian et $\mathrm{al}^{40}$ or Moorrees et al. ${ }^{41}$ There are some caveats to the use of this tooth however; the third molar has a high degree of congenital variability relating to its development, mineralization, and/or eruption, and it is also frequently impacted, and as such may also be removed as part of routine dental treatment. Differences in palatal dimensions, and the consequent delay in tooth mineralization, also contribute to demonstrated population differences in third molar development. Accordingly, it is imperative to apply population-specific data for dental age estimation. ${ }^{83-86}$

Olze et $\mathrm{al}^{87}$ analyzed the radiographic visibility of the periodontal ligament in the mandibular third molars for the purpose of age estimation. The visibility of the ligament was categorized into four stages (0-3): Stage 1 indicated that an individual has already attained the legally relevant age of 18 years, whereas Stages 2 and 3 showed beyond reasonable doubt that an individual was $>21$ years of age.

Age estimation methods developed for application in the living are required to be noninvasive, accurate, and medically ethical (eg, minimal radiation exposure), while ensuring compliance with other legalities, including confidentiality and consent. ${ }^{88,89}$ The radiographic examination of dental development is relatively noninvasive and only requires exposure to small radiation doses $(0.026 \mathrm{mSv})$ to acquire a suitable orthopantomogram (OPG).$^{90}$ This level of radiation is equivalent to 4.5 days of naturally occurring radiation exposure, and is thus ethically permissible. ${ }^{2}$ Further, the risks associated with radiation related to OPGs are considered harmless compared to other risks, such as fatal criminal assault, drowning, and homicide. ${ }^{89,90}$ The Australian Radiation Protection and Nuclear Safety Agency and the Australian Society of Forensic Odontology confirm that the radiation associated with dental X-rays is minimal. However, there is a general consensus among these agencies that all deliberate exposures to radiation should be justified, subject to control, and consider the potential damages arising due to the vulnerability and age (eg, radiographs being contradicted from birth to 2 years $^{62}$ ) of the individual. ${ }^{30}$

\section{Skeletal maturation}

The morphoscopic radiographic evaluation of skeletal development relative to full maturity continues to be used toward facilitating an estimation of age in living individuals. There are, however, acknowledged issues relating to improper application(s) and the sole reliance of any one skeletal indicator as a determinant of legal age. ${ }^{30}$ The hand and wrist bones develop at a known and predictable rate, and therefore, their development can be used to estimate age. Similarly, the medial clavicle has a particularly long developmental timeframe that spans adolescence through to adulthood, and is thus also frequently assessed.

\section{Hand-wrist}

There are two methods frequently consulted to estimate subadult age based on skeletal maturation in the handwrist complex: Gruelich and Pyle ${ }^{31}$ and Tanner et al. ${ }^{91-93}$ Other methods, in the interest of brevity, are not reviewed here. ${ }^{94-99}$ Those studies, while demonstrably effective within the populations upon which they were developed, have not been the focus of the same degree of validation in foreign 
populations and are thus less frequently applied for forensic age estimation.

Gruelich and Pyle's Radiographic Atlas of Skeletal Development of the Hand and Wrist ${ }^{31}$ is the method that is cited as being most frequently consulted in international protocols for hand-wrist subadult age estimation. ${ }^{100}$ The Gruelich and Pyle method is based on a radiographic atlas of skeletal maturity published by Todd; ${ }^{101}$ data from that study were assembled between 1931 and 1936 based on the analysis of British Caucasian children as part of the Brush Inquiry to chart the physical progression (eg, growth) of healthy children. The Gruelich and Pyle method presents anterior-posterior radiographs of known sex and age individuals that range from birth to 19 years of age. The radiographic developmental intervals are as follows: every 3 months up to 1 year of age; every 6 months between 1 year and 5 years of age; and every year from 5 years to 19 years of age with additional radiographs at ages 13.5 years and 15.5 years for females and males, respectively. A broad representation of developmental milestones, in conjunction with written descriptors, is presented to facilitate a more detailed examination of skeletal growth in younger individuals and assist in the assignation of a radiographic standard.

Application of the Gruelich and Pyle method involves the comparison of a hand-wrist X-ray of the individual in question to the atlas; the radiographic standard that is most developmentally similar is deemed to be indicative of the age of that individual. The stated accuracy of this method is between 0.6 years and 1.1 years. ${ }^{31}$ It is pertinent to note, however, that this atlas was not designed or intended for the estimation of forensic age; it is intended as a guide of skeletal growth for pediatricians, as specifically stated by the authors: "The system described in this atlas, for example, is intended to provide merely useful estimates of skeletal status". $31,44,94$

There have been many validation studies performed to test the accuracy and applicability of the Gruelich and Pyle method in a range of populations, for example, Indigenous Australian, ${ }^{102}$ Turkish, ${ }^{103}$ Iranian, ${ }^{104}$ Portuguese, ${ }^{105}$ Indian, ${ }^{106}$ and undifferentiated Australian. ${ }^{107}$ Those validation studies demonstrated that the Gruelich and Pyle method consistently overestimates age, for example, by 0.8 years and 0.5 years in Aboriginal Australian males and females, respectively, 0.171.1 years in Turkish females and $0.88-0.98$ years in Turkish males ( $>15$ years of age), and 0.7 years and $0.2-0.8$ years in Indian males and females, respectively. Brown and Grave ${ }^{102}$ and Moradi et al, ${ }^{104}$ however, stated that the Gruelich and Pyle method produced acceptable results when applied to their respective populations. Validation studies such as the latter, however, do highlight (in the interests of accuracy) the importance of population-specific standards in skeletal age estimation.

The Tanner-Whitehouse (TW) method is a mathematical (or scoring) method originally developed in 1962 (TW1) based on the analysis of anterior-posterior hand-wrist radiographs of British individuals between 1 and 21 years of age. The initial method involved the evaluation of 20 bones: radius; ulna; metacarpals 1, 3, and 5; and all carpals (excluding pisiform). The first revision (TW2) added an age estimation method using the radius, ulna, and short bones (the RUS skeletal age method - 13 bones in total). The second revision (TW3) was adjusted to use more contemporary data from a variety of populations (Belgian, Spanish, and American). ${ }^{108}$

The TW methods all involve evaluating successive developmental changes in a maximum of 20 individual bones in the hand and wrist. There are three individual approaches available that each utilize different bone combinations: RUS (radius, ulna, and selected metacarpals and phalanges), carpal (using all carpal bones excluding the pisiform), and the 20-bone system. Each stage of development is assigned a score from 0 to 1,000 (1,000 representing full skeletal maturity) that can be used to extrapolate skeletal maturity and derive an estimation of age using sex-specific percentile curves (3rd, 10th, 25th, 50th, 75th, 90th, and 95th) for each scoring method. As for the Gruelich and Pyle method, it should be noted that the TW system was not developed for forensic age estimation, but rather it was developed as an aid for pediatricians to evaluate growth disorders. ${ }^{92}$

Validation of the TW method has been performed in a variety of populations, including Japanese, ${ }^{109}$ Jamaican, ${ }^{110}$ Tasmanian, ${ }^{111}$ German, ${ }^{112}$ and Chinese. ${ }^{113}$ These studies indicate populational variability in the timing of skeletal development, which flows into differential levels of prediction accuracy. For example: the TW1 method underestimated age in the Jamaican population for individuals older than 10 years of age $(-0.692$ years in males; -0.626 years in females); the TW2 method underestimated age in the Japanese population by up to 2 years; and the TW3 method underestimated age by as much as 2 years in the Chinese population in individuals older than 6 years (males) and 10 years (females) of age. The TW2 method was found to be acceptable when applied to a Tasmanian Australian population, with no statistically significant difference between actual and predicted age based on hand-wrist skeletal development. 
In contrast to the methods reviewed above, Cameriere et al, ${ }^{94}$ developed a system designed specifically for forensic age estimation. This method is based on the calculation of a ratio between the total area of the carpal bones and the epiphyses of the ulna, radius, and carpals; a regression model for age prediction was presented, which within the Italian sample studied ( 89 male and 61 female individuals between 5 years and 17 years of age) had a Standard Error of the Estimate (SEE) of \pm 1.19 years. The relatively high accuracy of that method was confirmed by its application in a Slovenian population comprising 158 children and adolescents (between 6 years and 16 years of age); the regression model derived for that specific population had an SEE of \pm 0.96 years. ${ }^{99}$ Furthermore, there was no significant difference between the intercepts and slopes of the original Italian regression model and the one produced for the Slovenian population, thus implying a common regression model for both samples. ${ }^{100}$ That approach thus offers a promising method for the accurate assessment of age in living individuals.

\section{Medial clavicle}

The potential of evaluating clavicular development toward providing an estimation of age was largely established in the pioneering studies of Todd and D'Errico ${ }^{114}$ and McKern and Stewart. ${ }^{115}$ That research focused on the use of anatomical specimens to establish links between epiphyseal fusion in the medial clavicle and the age of a decedent. These methods established parameters for subcategorizing stages of epiphyseal fusion that provided the foundation from which contemporary studies are designed. The modern era bears witness to a growth in the need for age assessments in the living, in order to ascertain if a person has reached a particular age of legal relevance. Therefore, studies concentrating on the ossification of the medial clavicle as a means of determining age primarily rely on radiographic data and computed tomography (CT) scans. These studies focus on grading ossification in the medial clavicle and assigning each stage with a corresponding age range.

A seminal study in the quantification of fusion timing in the medial clavicle is Schmeling et al. ${ }^{116}$ The specific aim of that study was to provide a method of age estimation for living individuals that could subsequently be used to assess criminal liability. Radiographs of 873 German individuals (between the ages of 16 and 30 years) were evaluated according to five stages that were devised based on previous research. ${ }^{117,118}$ These stages are defined as follows:

Stage 1: Ossification center not ossified.

Stage 2: Ossification center ossified but epiphyseal cartilage not ossified.
Stage 3: Epiphyseal cartilage partially ossified.

Stage 4: Epiphyseal cartilage completely ossified but scar visible.

Stage 5: Epiphyseal cartilage completely fused with scar no longer visible.

The results of that study indicated that by attainment of Stage 5, all individuals (irrespective of sex) had reached the age of criminal culpability (mean age $>21$ years). On average, however, Stage 4 was not reached until 21.3 years and 20.0 years in males and females, respectively. This means that it is only statistically (and judicially) appropriate to infer that an individual assigned to Stages 1-4 inclusive is not deemed to have yet reached an age of criminal culpability. Although based on the analysis of radiographic images, quantification of the Schmeling method in CT scans was published the following year. ${ }^{119}$

Schmeling's method has been subjected to numerous validation studies each with specific aims to evaluate not only the accuracy of the method, but also the manner in which it is (or can be) applied, for example: 1) to investigate superimposition effects in standard posterior-anterior radiographs; ${ }^{120}$ 2) to assess the effect of slice thickness (scan resolution) on the accuracy and precision of stage assignation, and by association age estimation accuracy; ${ }^{121}$ and 3 ) to validate the accuracy of the method in geographically removed individuals (eg, most recently in a Western Australian population ${ }^{122}$ ), but there has been empirical assessment of the method in many other populations, including German, ${ }^{123}$ Serbian, ${ }^{124}$ and Italian. ${ }^{125}$

In relation to the aforementioned research relating to applications of the Schmeling method, the following important conclusions were drawn: 1) superimposition effects in the posterior-anterior radiographic imaging of the medial clavicle impede the assessment of fusion stage - the level of error introduced indicates that projection radiography of this structure is inappropriate and that $\mathrm{CT}$ is the exclusive imaging modality of choice; 2) optimal multiple detector CT slice thickness (scan resolution) for forensic age estimation purposes is $<1 \mathrm{~mm}$-thick slice CT scans result in lower intraand interobserver accordance; and 3) the Schmeling method is both reproducible and accurate for application in foreign populations. Considerable critical empirical evaluation of the Schmeling ${ }^{116}$ method implies that quantification of ossification in the medial clavicle is a valid noninvasive means of determining minimum age of legal liability in medico-legal cases.

\section{Future directions}

The present review has established the existence of a considerable body of research, and by association established 
methods, toward facilitating age estimations in living individuals. With increasing displacements, whether the result of natural disasters, economic sanctions, crimes against humanity, people smuggling, or other illegal activities, there is an associated increase in border crossings that result in an influx of undocumented individuals being referred to the legal system within the affected jurisdiction.

Accordingly, in the interests of justice, both ethically and legally, it is vital that age assessments are performed by appropriately qualified individuals with the required skill base; the resulting estimation must not only be able to withstand legal challenge, but also be cognizant of the humanitarian implications of an erroneous result. To that end, an appropriate individual is one who has specialized training in forensic medicine and/or allied disciplines that include forensic anthropology, forensic odontology, and where relevant, forensic psychology.

An intimate knowledge of basic human anatomy, including growth and development, however, while certainly necessary, is simply not enough. Any individual (or institution) tasked with performing an age estimation in living individuals must have a clear awareness of the limitation(s) of any method subsequently applied, including how to appropriately calculate the degree of uncertainty in the final estimation, a clear understanding of the influence of human biological variation and other extrinsic factors on the final estimation, and how to appropriately prepare a submission when called to act as an expert witness in a court of law.

It is also timely to revisit an important topical issue within the forensic anthropological discipline, the effect of applying "foreign standards" for estimating biological attributes in the human skeleton, which is generally accepted to result in a reduction in expected accuracy, the magnitude of which is proportionately related to the degree of dissimilarity (increasing biological distance) between the original reference sample and the individual to which those standards are being applied. ${ }^{126-128}$ Age assessments thus need to be performed using appropriate population-specific standards (statistical data). To achieve this, future research must be directed toward supporting appropriately qualified entities that have an established track record, and the required specialists and infrastructure, to evaluate appropriate methodological approaches with the aim of formulating statistically quantified contemporary population-specific standards for age estimation in living individuals; there is an obvious requirement for such data relating to populations from Southeast Asia, sub-Saharan Africa, South America, and the Middle East (among others).
Such research will need to abide by appropriate ethical guidelines for research involving living persons using noninvasive imaging techniques, and psychologically/emotionally sensitive approaches. Other important considerations are typically related to the finished product (age estimation standards), which, as outlined by Ritz-Timme et al, ${ }^{88}$ should fulfill the following specific demands:

- They must have been presented to the scientific community through peer-reviewed publication.

- Their accuracy must be tested using valid statistical procedures and described by clearly defined terms.

- The method must be accurate enough for routine forensic application.

We conclude this review with one last important consideration for the medico-legal community: is it unreasonable to expect that any single skeletal age marker examined in isolation can provide the requisite level of accuracy required to legally determine age at majority? To do so ignores documented research into human variability (growth patterns, genetic and environmental influences) that encompasses several decades of research. The latter lends further support for the application of a multifactorial approach (eg, use of multiple indicators of age, such as bone development relative to full maturity and dental status), for which there appears to be strong evidence showing that multifactorial techniques increase accuracy and help control for variation that may occur in any one single age indicator. ${ }^{129}$ Such approaches, encompassing appropriate diagnostic analyses, are already advocated in the established best practice recommendations of Schmeling et al. ${ }^{61}$

\section{Disclosure}

The authors declare no conflicts of interest in this work.

\section{References}

1. UNHCR. Children: protection and building resilience; 2013. Available from: http://www.unhcr.org/pages/49c3646c1e8.html. Accessed May 15, 2015.

2. Black S, Aggrawal A, Payne-James J, editors. Age Estimation in the Living: The Practitioner's Guide. Hoboken: John Wiley \& Sons; 2010.

3. Schlam L, Wood JP. Informed consent to the medical treatment of minors: law and practice. Health Matrix Clevel. 2000;10(2):141-174

4. Abbing HD. Age determination of unaccompanied asylum seeking minors in the European Union: a health law perspective. Eur J Health Law. 2011;18(1):11-25.

5. UNHCR. Detention guidelines: guidelines on the applicable criteria and standards relating to the detention of asylum-seekers and alternatives to detention; 2012. Available from: http://www.unhcr.org/refworld/ docid/503489533b8.html. Accessed March 24, 2015.

6. Phillips J, Spinks H. Immigration Detention in Australia. Parliamentary Library. Parliament of Australia; 2013. 
7. AHRC. The Forgotten Children: National Inquiry into Children in Immigration Detention. Sydney: Australian Human Rights Commission; 2014.

8. UNICEF. Child trafficking in East and South-East Asia: reversing the trend. UNICEF EAPRO; 2009. Available from: https://www.unicef.org. nz/store/doc/Unicefreport-reversingthetrend-Aug09.pdf.

9. UN. Protocol to Prevent, Suppress and Punish Trafficking in Persons, especially Women and Children. New York: United Nations; 2000.

10. UNODC. Global Report on Trafficking in Persons. Vienna: United Nations Office on Drugs and Crime; 2014.

11. Joudo Larsen J, Andrevski H, Lyneham S. Experiences of trafficked persons: an Indonesian sample. Trends Issues Crime Crim Justice. 2013;449:1-8.

12. Joudo Larsen J, Renshaw L. People trafficking in Australia. Trends Issues Crime Crim Justice. 2012;441:1-6.

13. UNIAP. The Mekong Region Human Country Datasheets on Human Trafficking 2010. Thailand: United Nations Inter-Agency Project on Human Trafficking; 2010.

14. Urbas G. The age of criminal responsibility. Trends Issues Crime Crim Justice. 2000;181:1-6.

15. Arthur R. Rethinking the criminal responsibility of young people in England. Eur J Crime Crim Law Crim Justice. 2012;20(1):13-29.

16. Bandalli S. Abolition of the presumption of doli incapax and the criminalisation of children. Howard J Crim Justice. 1998;37(2):114-123.

17. OHCHR. Guidelines for Action on Children in the Criminal Justice System. Vienna: Economic and Social Council, Resolution 1997/30 of 21 July 1997; 1997.

18. Fossi J. Young adult male prisoners: a short thematic report. Available from: http://www.justiceinspectorates.gov.uk/hmiprisons/wp-content/ uploads/sites/4/2014/06/Young_adult_male_prisoners.pdf. HM Inspectorate of Prisons; 2006. Accessed April 24, 2015.

19. Cesaroni C, Peterson-Badali M. The importance of institutional culture to the adjustment of incarcerated youth and young Adults. Can J Criminol Crim. 2013;55(4):563-575.

20. Carmichael JT. Punishing juvenile offenders as adults: an analysis of the social and political determinants of juvenile prison admissions across the United States. Sociol Focus. 2011;44(2):102-123.

21. Carpenter B, O'Brien E, Hayes S, Death J. Harm, responsibility, age, and consent. New Crim Law Rev. 2014;17(1):23-54.

22. Cattaneo C, Obertová Z, Ratnayake M, et al. Can facial proportions taken from images be of use for ageing in cases of suspected child pornography? A pilot study. Int J Legal Med. 2012;126(1):139-144.

23. OHCHR. Optional Protocol to the Convention on the Rights of the Child on the Sale of Children, Child Prostitution and Child Pornography. Geneva: OHCHR; 2000.

24. Mayer F, Arent T, Geserick G, et al. Age estimation based on pictures and videos presumably showing child or youth pornography. Int $J$ Legal Med. 2014;128(4):649-652.

25. Rosenbloom AL. Inaccuracy of age assessment from images of postpubescent subjects in cases of alleged child pornography. Int $J$ Legal Med. 2013;127(2):467-471.

26. UN. Strategic Framework 2011-2013. New York: United Nations; 2011.

27. Gee D, Goodman A. Young Age at Army Enlistment is Associated with Greater War Zone Risks: An Analysis of British Army Fatalities in Afghanistan. London: ForcesWatch; 2013.

28. Tosam MJ. The ethical and social implications of age-cheating in Africa. Int J Philos. 2015;3(1):1-11.

29. Malina RM. Skeletal age and age verification in youth sport. Sports Med. 2011;41(11):925-947.

30. AHRC. An Age of Uncertainty: Inquiry into the Treatment of Individuals Suspected of People Smuggling Offences Who Say that they are Children. Sydney, NSW: Australian Human Rights Commission; 2012.

31. Gruelich WW, Pyle SI. Radiographic Atals of Skeletal Development of the Hand and Wrist. Stanford: Stanford University Press; 1959.

32. Commonwealth-of-Australia. Detention of Indonesian Minors in Australia. Canberra: Legal and Constitutional Affairs References Committee; 2012.
33. Amnesty-International. This is Still Breaking People: Update on Human Rights Violations at Australia's Asylum Seeker Processing Centre on Manus Island, Papua New Guinea. Broadway, NSW: Amnesty International Australia; 2014.

34. Dyball K, McPhie G, Tudor C. Age Assessment Practice Guidance: An Age Assessment Pathway for Social Workers in Scotland. Glasgow: Scottish Refugee Council and Glasgow City Council; 2012.

35. SCEP. Position paper on age assessment in the context of separated children in Europe. Separated Children in Europe Programme; 2012. Available from: http://www.separated-children-europeprogrammeorg/ separated_children/good_practice/index.html.

36. Schmeling A, Garamendi PM, Prieto JL, Landa MI. Forensic age estimation in unaccompanied minors and young living adults. In: Vieira DN, editor. Forensic Medicine - From Old Problems to New Challenges. Rijeka: InTech; 2011:77-120.

37. Garamendi PM, Landa MI, Botella MC, Aleman I. Forensic age estimation on digital X-ray images: medial epiphyses of the clavicle and first rib ossification in relation to chronological age. J Forensic Sci. 2011;56(Suppl 1):S3-S12.

38. Schmidt S, Schiborr M, Pfeiffer H, Schmeling A, Schulz R. Sonographic examination of the apophysis of the iliac crest for forensic age estimation in living persons. Sci Justice. 2013;53(4):395-401.

39. Olze A, Reisinger W, Geserick G, Schmeling A. Age estimation of unaccompanied minors (Part II) dental aspects. Forensic Sci Int. 2006;159(Suppl 1):S65-S67.

40. Demirjian A, Goldstein H, Tanner JM. A new system of dental age assessment. Hum Biol. 1973;45(2):211-227.

41. Moorrees CF, Fanning EA, Hunt EE Jr. Age variation of formation stages for ten permanent teeth. $J$ Dent Res. 1963;42:1490-1502.

42. Marshall WA, Tanner JM. Variations in pattern of pubertal changes in girls. Arch Dis Child. 1969;44(235):291-303.

43. Franklin D. Forensic age estimation in human skeletal remains: current concepts and future directions. Legal Med. 2010;12(1):1-7.

44. Steyn M, Iscan MY. Metric sex determination from the pelvis in modern Greeks. Forensic Sci Int. 2008;179(1):86.e1-6.

45. Patriquin ML, Steyn M, Loth SR. Metric analysis of sex differences in South African black and white pelves. Forensic Sci Int. 2005;147(2-3): 119-127.

46. Herman-Giddens ME, Slora EJ, Wasserman RC, et al. Secondary sexual characteristics and menses in young girls seen in office practice: a study from the Pediatric Research in Office Settings network. Pediatrics. 1997;99(4):505-512.

47. Herman-Giddens ME, Steffes J, Harris D, et al. Secondary sexual characteristics in boys: data from the Pediatric Research in Office Settings Network. Pediatrics. 2012;130(5):e1058-e1068.

48. Wu TJ, Mendola P, Buck GM. Ethnic differences in the presence of secondary sex characteristics and menarche among US girls: the third National Health and Nutrition Examination survey, 1988-1994. Pediatrics. 2002;110(4):752-757.

49. Greil H, Kahl H. Assessment of developmental age: cross-sectional analysis of secondary sexual characteristics. Anthropol Anz. 2005;63(1): 63-75.

50. Crawley H. When is a Child Not a Child? Asylum, Age Disputes and the Process of Age Assessment. London: Immigration Law Practitioners' Association (ILPA); 2007 ISBN 1901833135.

51. Levenson R, Sharma A. The Health of Refugee Children: Guidelines for Paediatricians. London: Royal College of Paediatrics and Child Health; 1999 ISBN I 900954435.

52. Ubelaker DH. Human Skeletal Remains: Excavation, Analysis, Interpretation. Washington, DC: Taraxacum; 1978.

53. Scheuer L. Application of osteology to forensic medicine. Clin Anat. 2002;15:297-312.

54. UNHCR. Guidelines on International Protection: Child Asylum Claims Under Articles 1(A)2 and 1(F) of the 1951 Convention and/or 1967 Protocol Relating to the Status of Refugees. Geneva: UNHCR: The UN Refugee Agency; 2009. 
55. Harrison GA, Weiner JS, Tanner JM, Barnicot NA, editors. Human Biology: An Introduction to Human Evolution, Variation, Growth and Ecology. 3rd ed. Oxford: Oxford University Press; 1977.

56. Humphrey LT. Growth patterns in the modern human skeleton. Am J Phys Anthropol. 1998;105(1):57-72.

57. Khadilkar VV, Stanhope RG. Secular trends in puberty. Indian Pediatr. 2006;43:475-478.

58. Parent AS, Teilmann G, Juul A, Skakkebaek NE, Toppari J, Bourguignon JP. The timing of normal puberty and the age limits of sexual precocity: variations around the world, secular trends, and changes after migration. Endocr Rev. 2003;24(5):668-693.

59. Smith T, Brownlees L. Age Assessment Practices: A Literature Review and Annotated Bibliography. New York: United Nations Children's Fund (UNICEF); 2011.

60. Saunders S, DeVito C, Herring A, Southern R, Hoppa R. Accuracy tests of tooth formation age estimations for human skeletal remains. Am J Phys Anthropol. 1993;92(2):173-188.

61. Schmeling A, Grundmann C, Fuhrmann A, et al. Criteria for age estimation in living individuals. Int J Legal Med. 2008;122(6):457-460.

62. AlQahtani S. Dental age assessment. In: Catherine A, Carabott R, Evans S, editors. Forensic Odontology: An Essential Guide. West Sussex: John Wiley \& Sons, Ltd; 2014:137-166.

63. Blenkin M, Taylor J. Age estimation charts for a modern Australian population. Forensic Sci Int. 2012;221(1-3):106-112.

64. Clements EM, Davies-Thomas E, Pickett KG. Time of eruption of permanent teeth in British children in 1947-8. Br Med J. 1953;1(4825): 1421-1424.

65. Clements EMB, Daviesthomas E, Pickett KG. Time of eruption of permanent teeth in British children at independent, rural, and urban schools. Br Med J. 1957;1:1511-1513.

66. Schmeling A, Reisinger W, Geserick G, Olze A. Age estimation of unaccompanied minors. Part I. General considerations. Forensic Sci Int. 2006;159(Suppl 1):S61-S64.

67. Hughes TE, Bockmann MR, Seow K, et al. Strong genetic control of emergence of human primary incisors. J Dent Res. 2007;86(12): 1160-1165.

68. Schour I, Massler M. Studies in tooth development: the growth pattern of human teeth (Part 1). JADA. 1940;27(11):1778-1793.

69. Schour I, Massler M. Studies in tooth development: the growth pattern of human teeth (Part 2). JADA. 1940;27(12):1918-1931.

70. Ubelaker DH. Human Skeletal Remains. 2nd ed. Washington, DC: Taraxacum; 1989.

71. Anderson DL, Thompson GW, Popovich F. Age of attainment of mineralization stages of the permanent dentition. J Forensic Sci. 1976;21(1):191-200.

72. Liversidge HM. Permanent tooth formation as a method of estimating age. Front Oral Biol. 2009;13:153-157.

73. AlQahtani SJ, Hector MP, Liversidge HM. Brief communication: the London atlas of human tooth development and eruption. Am J Phys Anthropol. 2010;142(3):481-490.

74. AlQahtani SJ, Hector MP, Liversidge HM. Accuracy of dental age estimation charts: Schour and Massler, Ubelaker and the London Atlas. Am J Phys Anthropol. 2014;154(1):70-78.

75. Phillips VM, van Wyk Kotze TJ. Testing standard methods of dental age estimation by Moorrees, Fanning and Hunt and Demirjian, Goldstein and Tanner on three South African children samples. J Forensic Odontostomatol. 2009;27(2):20-28.

76. Harris EF, Buck AL. Tooth mineralization: a technical note on the Moorrees-Fanning-Hunt standards. Dent Anthropol. 2002;16:15-20.

77. Blenkin MRB, Evans W. Age estimation from the teeth using a modified Demirjian system. J Forensic Sci. 2010;55(6):1504-1508.

78. Tunc ES, Koyuturk AE. Dental age assessment using Demirjian's method on northern Turkish children. Forensic Sci Int. 2008;175(1): 23-26.

79. Koshy S, Tandon S. Dental age assessment: the applicability of Demirjian's method in south Indian children. Forensic Sci Int. 1998; 94(1-2):73-85.
80. Chaillet N, Willems G, Demirjian A. Dental maturity in Belgian children using Demirjian's method and polynomial functions: new standard curves for forensic and clinical use. J Forensic Odontostomatol. 2004;22(2):18-27.

81. Senn DR, Weems RA. Manual of Forensic Odontology. 5th ed. Boca Raton, FL: CRC Press; 2013.

82. Karkhanis S, Mack P, Franklin D. Dental age estimation standards for a Western Australian population. Forensic Sci Int. 2015;pii: S0379-0738(15)00256-X. Epub ahead of print.

83. Mincer HH, Harris EF, Berryman HE. The ABFO study of third molar development and its use as an estimator of chronological age. J Forensic Sci. 1993;38(2):379-390.

84. Olze A, Schmeling A, Taniguchi M, et al. Forensic age estimation in living subjects: the ethnic factor in wisdom tooth mineralization. Int J Legal Med. 2004;118(3):170-173.

85. Olze A, van Niekerk P, Ishikawa T, et al. Comparative study on the effect of ethnicity on wisdom tooth eruption. Int J Legal Med. 2007; 121(6):445-448.

86. Sisman Y, Uysal T, Yagmur F, Ramoglu SI. Third-molar development in relation to chronologic age in Turkish children and young adults. Angle Orthod. 2007;77(6):1040-1045.

87. Olze A, Solheim T, Schulz R, Kupfer M, Pfeiffer H, Schmeling A. Assessment of the radiographic visibility of the periodontal ligament in the lower third molars for the purpose of forensic age estimation in living individuals. Int J Legal Med. 2010;124(5):445-448.

88. Ritz-Timme S, Cattaneo C, Collins MJ, et al. Age estimation: the state of the art in relation to the specific demands of forensic practise. Int J Legal Med. 2000;113(3):129-136.

89. Cunha E, Baccino E, Martrille L, et al. The problem of aging human remains and living individuals: a review. Forensic Sci Int. 2009; 193(1-3):1-13.

90. Ramsthaler F, Proschek P, Betz W, Verhoff MA. How reliable are the risk estimates for X-ray examinations in forensic age estimations? A safety update. Int J Legal Med. 2009;123(3):199-204.

91. Tanner JM, Whitehouse RJ, Healy MRJ. A New System for Estimating Skeletal Maturity from the Hand and Wrist with Standards Derived from a Study of 2,600 Healthy British Children (Part II) The Scoring System. Paris: International Child Centre; 1962.

92. Tanner JM, Whitehouse RH, Cameron N, Marshall WA, Healy MJR, Goldstein H. Assessment of Skeletal Maturity and Prediction of Adult Height. London: Academic Press; 1983.

93. Tanner JM, Healy MRJ, Goldstein H, et al. Assessment of Skeletal Maturity and Prediction of Adult Height (TW3). London: WB Saunders; 2001.

94. Cameriere R, Ferrante L, Mirtella D, Cingolani M. Carpals and epiphyses of radius and ulna as age indicators. Int J Legal Med. 2006;120(3): 143-146.

95. Chumela WC, Roche AF, Thissen D. The FELS method of assessing the skeletal maturity of the hand-wrist. Am J Hum Biol. 1989;1(2):175-183.

96. Roche AF, Chumlea WC, Thissen D. Assessing the Skeletal Maturity of the Hand-Wrist: Fels Method. Springfield: Thomas; 1988.

97. Thiemann HH, Nitz I. Röntgenatlas der normalen Hand im Kindesalter. Leipzig: Thieme; 1991.

98. Gilsanz V, Ratib O. Hand Bone Age: A Digital Atlas of Skeletal Maturity. Berline: Springer-Verlag; 2005.

99. Gilsanz V, Ratib O. Hand Bone Age: A Digitial Atlas of Skeletal Maturity. 2nd ed. Berlin: Springer-Verlag; 2011.

100. Cameriere R, Ferrante L, Ermenc B, Mirtella D, Strus K. Age estimation using carpals: study of a Slovenian sample to test Cameriere's method. Forensic Sci Int. 2008;174(2-3):178-181.

101. Todd TW. Atlas of Skeletal Maturation. Part 1: The Hand. St Louis: Mosby; 1937.

102. Brown T, Grave KC. Skeletal maturation in Australian Aborigines Aust Paediatr J. 1976;12(1):24-30.

103. Buken B, Safak AA, Yazici B, Buken E, Mayda AS. Is the assessment of bone age by the Greulich-Pyle method reliable at forensic age estimation for Turkish children? Forensic Sci Int. 2007;173(2-3): 146-153. 
104. Moradi M, Sirous M, Morovatti P. The reliability of skeletal age determination in an Iranian sample using Greulich and Pyle method. Forensic Sci Int. 2012;223(1-3):372.e1-372.e4.

105. Santos C, Ferreira M, Alves FC, Cunha E. Comparative study of Greulich and Pyle atlas and maturos 4.0 program for age estimation in a Portuguese sample. Forensic Sci Int. 2011;212(1-3):276.e1-276.e7.

106. Patil ST, Parchand MP, Meshram MM, Kamdi NY. Applicability of Greulich and Pyle skeletal age standards to Indian children. Forensic Sci Int. 2012;216(1-3):200.e1-200.e4.

107. Paxton ML, Lamont AC, Stillwell AP. The reliability of the GreulichPyle method in bone age determination among Australian children. J Med Imaging Radiat Oncol. 2013;57(1):21-24.

108. Tanner J, Oshman D, Bahhage F, Healy M. Tanner-Whitehouse bone age reference values for North American children. J Pediatr. 1997;131(1 pt 1):34-40.

109. Ashizawa K, Asami T, Anzo M, et al. Standard RUS skeletal maturation of Tokyo children. Ann Hum Biol. 1996;23(6):457-469.

110. Marshall WA, Ashcroft MT, Bryan G. Skeletal maturation of the hand and wrist in Jamaican children. Hum Biol. 1970;42(3):419-435.

111. Powell S, Ma D, Jones G. Determinants of skeletal age deviation in a cross-sectional study. J Clin Endocrinol Metab. 2008;93(2):521-526.

112. Schmidt S, Baumann U, Schulz R, Reisinger W, Schmeling A. Study of age dependence of epiphyseal ossification of the hand skeleton. Int J Legal Med. 2008;122(1):51-54.

113. Zhang SY, Liu LJ, Wu ZL, et al. Standards of TW3 skeletal maturity for Chinese children. Ann Hum Biol. 2008;35(3):349-354.

114. Todd TW, D'Errico J. The clavicular epiphyses. Am J Anat. 1928; 41(1):25-50

115. McKern TW, Stewart TD. Skeletal Age Changes in Young American Males, Analyzed from the Standpoint of Identification. Natick, MA: Quartermaster Research and Development Center, US Army; 1957.

116. Schmeling A, Schulz R, Reisinger W, Muhler M, Wernecke KD, Geserick G. Studies on the time frame for ossification of the medial clavicular epiphyseal cartilage in conventional radiography. Int J Legal Med. 2004;118(1):5-8.

117. Kreitner KF, Schweden FJ, Riepert T, Nafe B, Thelen M. Bone age determination based on the study of the medial extremity of the clavicle. Eur Radiol. 1998;8(7):1116-1122.
118. Jit I, Kulkarni M. Times of appearance and fusion of epiphysis at the medial end of the clavicle. Ind J Med Res. 1976;64(5):773-782.

119. Schulz R, Muhler M, Mutze S, Schmidt S, Reisinger W, Schmeling A. Studies on the time frame for ossification of the medial epiphysis of the clavicle as revealed by CT scans. Int J Legal Med. 2005;119(3): $142-145$.

120. Wittschieber D, Ottow C, Vieth V, et al. Projection radiography of the clavicle: still recommendable for forensic age diagnostics in living individuals? Int J Legal Med. 2015;129:187-193.

121. Muhler M, Schulz R, Schmidt S, Schmeling A, Reisinger W. The influence of slice thickness on assessment of clavicle ossification in forensic age diagnostics. Int J Legal Med. 2006;120(1):15-17.

122. Franklin D, Flavel A. CT evaluation of timing for ossification of the medial clavicular epiphysis in a contemporary Western Australian population. Int J Legal Med. 2015;129(3):583-594.

123. Schulze D, Rother U, Fuhrmann A, Richel S, Faulmann G, Heiland M. Correlation of age and ossification of the medial clavicular epiphysis using computed tomography. Forensic Sci Int. 2006;158(2-3): 184-189.

124. Milenkovic P, Djukic K, Djonic D, Milovanovic P, Djuric M. Skeletal age estimation based on medial clavicle - a test of the method reliability. Int J Legal Med. 2013;127(3):667-676.

125. Cameriere R, De Luca S, De Angelis D, et al. Reliability of Schmeling's stages of ossification of medial clavicular epiphyses and its validity to assess 18 years of age in living subjects. Int J Legal Med. 2012;126(6):923-932.

126. Franklin D, Freedman L, Milne N. Sexual dimorphism and discriminant function sexing in indigenous South African crania. Homo. 2005;55(3):213-228.

127. Franklin D, Cardini A, Flavel A, Kuliukas A. Estimation of sex from cranial measurements in a Western Australian population. Forensic Sci Int. 2013;229(1-3):158.e1-158.e8.

128. Franklin D, Cardini A, Flavel A, Marks MK. Morphometric analysis of pelvic sexual dimorphism in a contemporary Western Australian population. Int J Legal Med. 2014;128(5):861-872.

129. SWGANTH. Age Estimation. The Scientific Working Group for Forensic Anthropology; 2013. Available from: http://www.swganth. org/products--drafts.html.
Research and Reports in Forensic Medical Science

\section{Publish your work in this journal}

Research and Reports in Forensic Medical Science is an international, peer-reviewed, open access journal publishing original research, reports, reviews and commentaries on all areas of forensic medical science. The manuscript management system is completely online and includes a

\section{Dovepress}

very quick and fair peer-review system. Visit http://www.dovepress.com/ testimonials.php to read real quotes from published authors. 